\title{
A few steps closer to answering the unanswered questions about higher calorie refeeding
}

\author{
Andrea K. Garber
}

\begin{abstract}
Keywords: Anorexia nervosa, Eating disorder, Refeeding, High calorie, Low calorie, Safety, Nutritional rehabilitation, Refeeding syndrome
\end{abstract}

Refeeding is the first step in long-term nutritional rehabilitation of patients with anorexia nervosa (AN). It may begin in the outpatient setting or in the hospital, if close medical and/or psychiatric monitoring is needed. In either case, early weight gain appears to be crucial for recovery. In hospital, faster weight gain [1] and higher weight upon discharge $[2,3]$ predict weight recovery at 1 year. In outpatient psychotherapy, substantial early gain (at least $0.43-0.86 \mathrm{~kg} /$ week during the first 4 weeks) predicts both weight and cognitive recovery at 12 months [4]. The importance of weight gain, however, must be balanced with the need for safety. Around the time of World War II, deaths were documented during refeeding in prisoners of war and the refeeding syndrome was first described $[5,6]$. These sobering reports launched a 60-year period of extremely conservative approaches, with consensus-based recommendations for AN beginning around $1200 \mathrm{cal}$ per day $(\mathrm{kcal} / \mathrm{d})$ and advancing slowly by $200 \mathrm{kcal}$ every other day [7-9]. During the decades that this "start low and go slow" approach has been the standard of care in AN, only a handful of cases of the refeeding syndrome have been reported and this has been lauded as an indication of the safety. However, recent studies linking LCR to poor weight gain [10-12] and prolonged hospital stays $[11,12]$ have contributed to recognition of the "underfeeding syndrome" [13] and spurred interest in Higher Calorie Refeeding (HCR).

There is no consensus as of yet on the definition of HCR, and clinical approaches vary widely. Nevertheless, it is clearly a "hot topic": $85 \%$ of the refeeding studies

Correspondence: andrea.garber@ucsf.edu

Department of Pediatrics, Division of Adolescent and Young Adult Medicine, University of California, San Francisco, Benioff Children's Hospital, 3333 California St., Suite 245, Box 0503, San Francisco, CA 94118, USA published from 2010 to 2015 started with higher calories than recommended ( $\geq 1400 \mathrm{kcal} / \mathrm{d})$ [14]. This issue of the Journal of Eating Disorders is on the frontline of this movement. The studies published in this issue share core attributes: all three are retrospective chart reviews examining short-term, meal-based refeeding in moderately malnourished [75-85\% of median Body Mass Index (mBMI)] adolescents (ages 14-16 on average), who were diagnosed with eating disorders and hospitalized for medical stabilization. However, several unique features further our understanding by addressing important unanswered questions.

Is HCR safe? No study to date has established the safety of a refeeding approach, and perhaps no study could ever truly do so, since a massive study population would be required to examine the full spectrum of features of the rarely occurring refeeding syndrome. Thus, we must continue to use very careful language around safety, acknowledging that electrolyte shifts are at best only early indicators of the risk for development of the refeeding syndrome. This was the focus of Maginot et al., who compared serum phosphorus, potassium and magnesium during refeeding on LCR (starting around $1185 \mathrm{kcal} / \mathrm{d}$ and advancing by about $90 \mathrm{kcal} / \mathrm{d}$ ) versus HCR (starting at $1781 \mathrm{kcal} / \mathrm{d}$ on average and advancing by about $100 \mathrm{kcal} / \mathrm{d}$ ). Among 89 participants, the authors found no association between starting kcal prescription and hypophosphatemia, hypokalemia or hypomagnesaemia in the first $72 \mathrm{~h}$. Another unique aspect of this study was its subanalysis of severely malnourished patients: almost $30 \%$ of the study population was admitted with $\mathrm{mBMI}<75 \%$. Only two prior studies of HCR have had sufficient sample sizes to do this (as reviewed in ref 14), both reporting higher rates of refeeding hypophosphatemia 
in such patients. Maginot et al.s' finding that admission $\%$ mBMI (not kcal prescription) was the best predictor of hypophosphatemia is consistent with the current evidence [15] and warrants continued caution when refeeding severely malnourished patients.

Is HCR appropriate for all eating disorder patients? The $5^{\text {th }}$ Edition of the Diagnostic and Statistical Manual (DSM-5) has improved the accuracy and broadened the range of eating disorder diagnoses [16]. This shift is reflected in the hospitalized population: more than onethird of the 215 participants in the Peebles et al. study were diagnosed with eating disorders other than AN, including Bulimia Nervosa (BN), Avoidant and Restrictive Food Intake Disorder (ARFID), Atypical AN (AAN), Purging Disorder or Unspecified Food and Eating Disorder (UFED). This study took a unique quality improvement perspective, providing a detailed description of a multi-system refeeding approach including parents. Starting with an average of $1466 \mathrm{kcal}$ and advancing by $233 \mathrm{kcal} / \mathrm{d}$, all groups gained significant weight during the average 11 day hospital stay and this was sustained in the $74 \%$ of participants who followed-up at 4 weeks. This finding demonstrates that the program's approach to refeeding is consistent with their non- weight-biased belief that all patients who are medically compromised to the point of meeting hospital admission criteria should gain initial weight, regardless of specific diagnosis.

Does HCR lead to better outcomes? Relapse in the first year of recovery is common: up to $43 \%$ of patients will require medical rehospitalization within 12 months of discharge [17]. Practitioners have voiced understandable concerns that the shorter hospitalizations associated with rapid refeeding could create a "revolving door" of frequent rehospitalizations. The study by Smith et al. is the first to examine the relationship between the caloric level of refeeding and outcomes beyond the hospital stay. Participants were refed beginning around $1585 \mathrm{kcal} / \mathrm{d}$ and advanced variably to achieve a weight regain of 130-200 g per day (average advancement was $146 \mathrm{kcal} / \mathrm{d}$ ). In 4 weeks, $70 \%$ of the 129 participants followed-up and 9\% were readmitted. In growth models, faster caloric advancement was associated with greater weight gain in hospital but not weight at 4-week follow-up or readmission. While this finding may disappoint those who hoped that HCR would produce better post-hospital outcomes, it should be viewed as a positive sign that equally good mid-term recovery may be achieved over a shorter hospital stay using HCR.

Future directions - The studies highlighted here break new ground and point to several priority areas for future studies of refeeding. The first priority must be safety. Fortunately, no study of HCR to date (including the three here) has reported a case of the refeeding syndrome. However, this should not be misinterpreted to mean that HCR carries no risk. In fact, about half of the participants in both the Maginot et al. and Smith et al. studies developed hypophosphatemia. Thus, the collective research supports the feasibility of HCR in the highly controlled hospital setting with close medical monitoring and electrolyte replacement. Even within these settings, wide variations in approaches to care may explain disparate findings, such as the $77 \%$ of the participants in Maginot et al. who required electrolyte correction, compared to only $14.2 \%$ in Peebles et al. A second priority for future investigations is to follow the example of the present studies and describe feeding protocols in detail (Peebles et al. set the high bar here). Two-thirds of "refeeding" studies published from 2010 to 2015 failed to provide basic information such as caloric level [14], which hampers interpretation and reproducibility of findings. Third, future studies should further extend the 4-week follow-up period of Smith et al. and Peebles et al. to examine longer-term outcomes of refeeding. Any such proposals would be well supported by a large scale Randomized Controlled Trial (RCT) showing that long hospital stays do not improve 1-year recovery rates in AN [18]. On that note, all of these research priorities could be simultaneously addressed with well-designed RCTs that directly compare approaches to feeding. RCTs would also address the problem of selection bias, whereby physicians tend to prescribe LCR to more malnourished patients. This problem has plagued our own work $[10,11]$ and was likely at play in Maginot et al., where the LCR group tended to have lower admit weight than the HCR group. Without randomization, such bias is nearly unavoidable, since the decision to exercise caution with more malnourished patients is indeed evidenced-based [15]. The tremendous amount of time and resources that such RCTs will require may seem daunting, but to skip this crucial step in scientific inquiry and adopt HCR as the new standard of care for AN would be to risk embarking on another 65 years of consensus-based (rather than evidence-based) care. Our patients deserve more! Bravo to the authors highlighted here for paving the way.

\section{Abbreviations \\ AN: Anorexia nervosa; HCR: Higher calorie refeeding; LCR: Lower Calorie Refeeding; mBMI: median Body Mass Index; RCT: Randomized Controlled} Trial; AN: Anorexia Nervosa

\section{Funding}

Not applicable.

Availability of data and materials

Not applicable.

Author's contributions

AG was the sole contributor to writing this manuscript. 


\section{Author's information}

Dr. Garber is an Associate Professor of Pediatrics in the Division of Adolescent Medicine at the University of California, San Francisco (UCSF) and Chief Nutritionist for the Adolescent and Young Adult Eating Disorders Program at UCSF Benioff Children's Hospital. She earned her PhD in Human and Clinical Nutrition at the University of WisconsinMadison and RD (Registered Dietitian) from UCSF. She teaches and trains medical and graduate students, pediatric residents, and fellows in adolescent medicine and child psychiatry through her role in the Leadership Education in Adolescent Health program at UCSF and a Maternal Child Health-Nutrition training program in collaboration with the School of Public Health at UC Berkeley. She also teaches in the classroom, as the Nutrition Theme Director for the UCSF School of Medicine. Her research focuses on eating disorders. She is the Principal Investigator on two $\mathrm{NIH}$-funded studies of refeeding in adolescents with anorexia nervosa and co-Investigator on a UC system-wide effort to coordinate electronic medical record data. In the past, she has been active public health nutrition research on fast food and California's menu labeling legislation. In the community, Dr. Garber has been a member of the San Francisco Board of Supervisors Childhood Obesity Task Force, co-Chair of the Mayor's Shape Up initiative, and an invited participant to Governor Schwarzenegger's Obesity Summit.

\section{Competing interests}

The author declares that she has no competing interests.

\section{Consent for publication}

Not applicable.

\section{Ethics approval and consent to participate}

Not applicable.

Received: 3 February 2017 Accepted: 16 February 2017

Published online: 01 March 2017

\section{References}

1. Lund BC, Hernandez ER, Yates WR, et al. Rate of inpatient weight restoration predicts outcome in anorexia nervosa. Int J Eat Disord. 2009;42:301-5.

2. Baran SA, Weltzin TE, Kaye WH. Low discharge weight and outcome in anorexia nervosa. Am J Psychiatry. 1995;152:1070-2.

3. Lock J, Litt I. What predicts maintenance of weight for adolescents medically hospitalized for anorexia nervosa? Eat Disord. 2003;11:1-7.

4. Le Grange D, Accurso EC, Lock J, et al. Early weight gain predicts outcome in two treatments for adolescent anorexia nervosa. Int J Eat Disord. 2014;47: 124-9.

5. Schnitker MA, Mattman PE, Bliss TL. A clinical study of malnutrition in Japanese prisoners of war. Ann Intern Med. 1951;35:69-96.

6. Keys A, Brozek K, Henschel A, Mickelsen O, Taylor HL. The biology of human starvation. Minneapolis: University of Minnesota Press; 1950.

7. Practice guideline for the treatment of patients with eating disorders (revision). American Psychiatric Association Work Group on Eating Disorders. Am J Psychiatry. 2000;157 Suppl 1:1-39.

8. American Psychiatric Association. Treatment of patients with eating disorders, third edition. American Psychiatric Association. Am J Psychiatry. 2006;163 Suppl 7:4-54.

9. American Dietetic Association. Position of the American Dietetic Association: Nutrition intervention in the treatment of anorexia nervosa, bulimia nervosa, and other eating disorders. J Am Diet Assoc. 2006;106: 2073-82.

10. Garber AK, Michihata N, Hetnal K, et al. A prospective examination of weight gain in hospitalized adolescents with anorexia nervosa on a recommended refeeding protocol. J Adolesc Health. 2012;50:24-9.

11. Garber AK, Mauldin K, Michihata N, et al. Higher calorie diets increase rate of weight gain and shorten hospital stay in hospitalized adolescents with anorexia nervosa. J Adolesc Health. 2013;53:579-84.

12. Golden $\mathrm{NH}$, Keane-Miller C, Sainani $\mathrm{KL}$, et al. Higher caloric intake in hospitalized adolescents with anorexia nervosa is associated with reduced length of stay and no increased rate of refeeding syndrome. J Adolesc Health. 2013;53:573-8.
13. MARSIPAN Working Group. Management of Really Sick Patients with Anorexia Nervosa. Available at: http://www.rcpsych.ac.uk/pdf/CR189_a.pdf. Accessed 25 June 2012.

14. Garber AK, Sawyer SM, Golden NH, et al. A systematic review of approaches to refeeding in patients with anorexia nervosa. Int J Eat Disord. 2016;49: 293-310.

15. Society for Adolescent Health and Medicine. Refeeding hypophosphatemia in hospitalized adolescents with anorexia nervosa: a position statement of the society for adolescent health and medicine. J Adolesc Health. 2014;55: 455-7.

16. Ornstein RM, Rosen DS, Mammel KA, et al. Distribution of eating disorders in children and adolescents using the proposed DSM-5 criteria for feeding and eating disorders. J Adolesc Health. 2013;53:303-5.

17. Steinhausen HC, Grigoroiu-Serbanescu M, Boyadjieva S, et al. Course and predictors of rehospitalization in adolescent anorexia nervosa in a multisite study. Int J Eat Disord. 2008;41:29-36.

18. Madden S, Miskovic-Wheatley J, Wallis A, et al. A randomized controlled trial of in-patient treatment for anorexia nervosa in medically unstable adolescents. Psychol Med. 2015;45:415-27.

\section{Submit your next manuscript to BioMed Central and we will help you at every step:}

- We accept pre-submission inquiries

- Our selector tool helps you to find the most relevant journal

- We provide round the clock customer support

- Convenient online submission

- Thorough peer review

- Inclusion in PubMed and all major indexing services

- Maximum visibility for your research

Submit your manuscript at www.biomedcentral.com/submit
) Biomed Central 